\title{
Clinical performance and patient outcome after simulation-based training in prevention and management of postpartum haemorrhage: an educational intervention study in a low-resource setting
}

Ellen Nelissen ${ }^{1,2^{*}}$, Hege Ersdal ${ }^{1,3}$, Estomih Mduma', Bjørg Evjen-Olsen ${ }^{4,5}$, Jos Twisk ${ }^{6,7}$, Jacqueline Broerse ${ }^{8}$, Jos van Roosmalen ${ }^{8,9}$ and Jelle Stekelenburg ${ }^{10,11}$

\begin{abstract}
Background: Postpartum haemorrhage (PPH) is a major cause of maternal mortality. Prevention and adequate treatment are therefore important. However, most births in low-resource settings are not attended by skilled providers, and knowledge and skills of healthcare workers that are available are low. Simulation-based training effectively improves knowledge and simulated skills, but the effectiveness of training on clinical behaviour and patient outcome is not yet fully understood. The aim of this study was to assess the effect of obstetric simulationbased training on the incidence of PPH and clinical performance of basic delivery skills and management of PPH.

Methods: A prospective educational intervention study was performed in a rural referral hospital in Tanzania. Sixteen research assistants observed all births with a gestational age of more than 28 weeks from May 2011 to June 2013. In March 2012 a half-day obstetric simulation-based training in management of PPH was introduced. Observations before and after training were compared. The main outcome measures were incidence of PPH (500-1000 ml and >1000 ml), use and timing of administration of uterotonic drugs, removal of placenta by controlled cord traction, uterine massage, examination of the placenta, management of PPH (>500 ml), and maternal and neonatal mortality at $24 \mathrm{~h}$.

Results: Three thousand six hundred twenty two births before and 5824 births after intervention were included. The incidence of PPH (500-1000 ml) significantly reduced from 2.1\% to $1.3 \%$ after training (effect size Cohen's $d=0.07$ ). The proportion of women that received oxytocin (87.8\%), removal of placenta by controlled cord traction (96.5\%), and uterine massage after birth (93.0\%) significantly increased after training (to 91.7\%, 98.8\%, 99.0\% respectively). The proportion of women who received oxytocin as part of management of PPH increased significantly (before training 43. 0\%, after training 61.2\%). Other skills in management of PPH improved (uterine massage, examination of birth canal, bimanual uterine compression), but these were not statistically significant.
\end{abstract}

Conclusions: The introduction of obstetric simulation-based training was associated with a 38\% reduction in incidence of PPH and improved clinical performance of basic delivery skills and management of PPH.

Keywords: Obstetrics, Simulation-based training, Postpartum haemorrhage, Low-resource settings, Education

\footnotetext{
* Correspondence: ellen.nelissen@bristol.ac.uk

${ }^{1}$ Research Department, Haydom Lutheran Hospital, POB 9000, Haydom,

Manyara, Tanzania

${ }^{2}$ Department of Obstetrics and Gynaecology, Southmead Hospital,

Southmead Road, Bristol BS10 5NB, UK

Full list of author information is available at the end of the article
} 


\section{Background}

Postpartum haemorrhage is a major cause of maternal mortality. [1] The prevalence of postpartum haemorrhage ranges from $11 \%$ to $26 \%$ for blood loss more than $500 \mathrm{ml}$, and from 2 to $5 \%$ for blood loss more than $1000 \mathrm{ml}$. [2, 3] More than 55\% of pregnant women in Africa suffer from anaemia in pregnancy, [4] and do not have much reserve when postpartum haemorrhage occurs. Prevention and prompt, adequate treatment of postpartum haemorrhage is therefore important. However, many births in sub-Sahara Africa are not attended by skilled providers. [5] In Tanzania only $51 \%$ of all births are assisted by a skilled provider. [6] In addition, knowledge and skills of providers are low $[5,7]$ and inhouse training facilities to keep knowledge and skills of healthcare workers up to date hardly exist in lowresource settings. [5, 8] Therefore, Jhpiego (John Hopkins Programme for International Education in Gynaecology and Obstetrics) and Laerdal Global Health developed Helping Mothers Survive Bleeding After Birth (HMS BAB), a simulation-based training package targeted at healthcare workers in areas with a high burden of maternal morbidity and mortality. [9] The training package focuses on basic delivery care, active management of third stage of labour, and treatment of postpartum haemorrhage. [10] Simulation-based education, and HMS BAB in specific, has been shown to effectively increase knowledge, skills, and confidence of healthcare workers [8, 11-13] and is intended to reduce maternal morbidity and mortality caused by postpartum haemorrhage.

The four-level Kirkpatrick model is often used to evaluate training programmes (Fig. 1). [14] Most publications regarding evaluation of training programmes only address the first two levels of this model. [12, 15] Improvement in clinical performance of healthcare workers and patient outcome is the ultimate goal, however most research in this area has been limited to neonatal outcome. $[16,17]$ There is mounting evidence to suggest that training in emergency obstetric care improves maternal outcome. [18-22]

The aim of this study was to assess the effect of obstetric simulation-based training on the incidence of postpartum haemorrhage (Kirkpatrick level 4) and clinical performance of basic delivery skills and management of postpartum haemorrhage (Kirkpatrick level 3) in a low-resource setting.

\section{Methods}

\section{Study design and setting}

We conducted a prospective educational intervention study at Haydom Lutheran Hospital, a rural referral hospital in Northern Tanzania. During the study period, the hospital had 420 beds and provided free reproductive health services including comprehensive emergency obstetric care. This incorporated facilities for basic delivery (including the provision of antibiotics, uterotonics, and anticonvulsants), assisted vaginal delivery, removal of retained products of conception, blood transfusion, and caesarean section. Extrapolating from the 2002 census, the immediate catchment area of the hospital covered a population of approximately 350,000 in 2012, while the greater reference area covered a population of approximately 2,357,000. [23] The annual number of hospitalbased births at the time of the study was approximately 5000 .

\section{Intervention}

The educational intervention took place in March 2012. An overview of research activities is depicted in Fig. 2. Data were prospectively collected from the 25th of May 2011 to the 25th of June 2013. A multi-professional group of clinicians, nurse-midwives, medical attendants (nurse aides without formal medical education), and

Level 4 measures change in patient outcome due to training

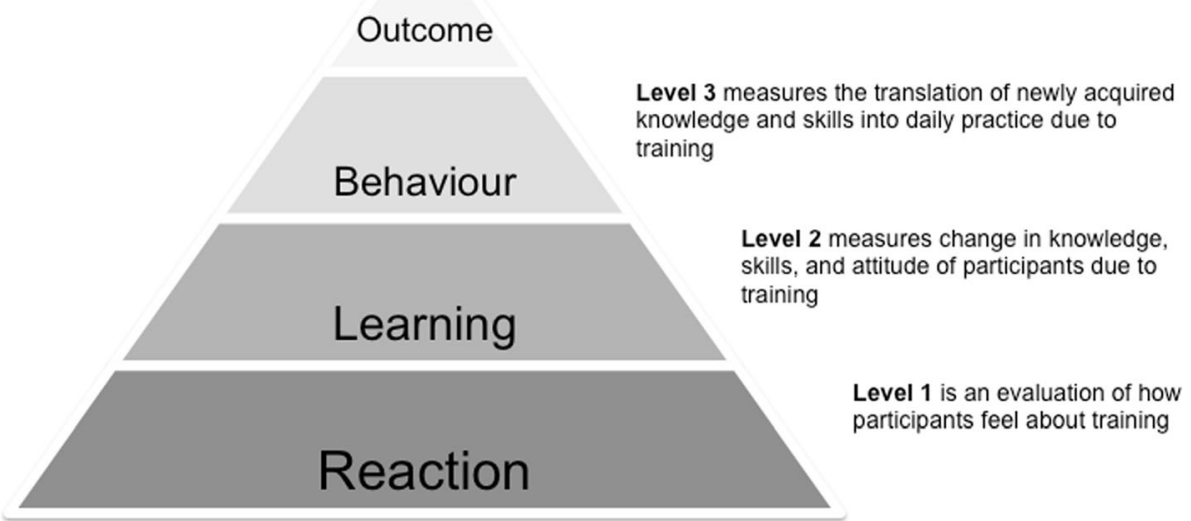

Fig. 1 Kirkpatrick model for evaluating training programmes 


\section{Educational intervention study}

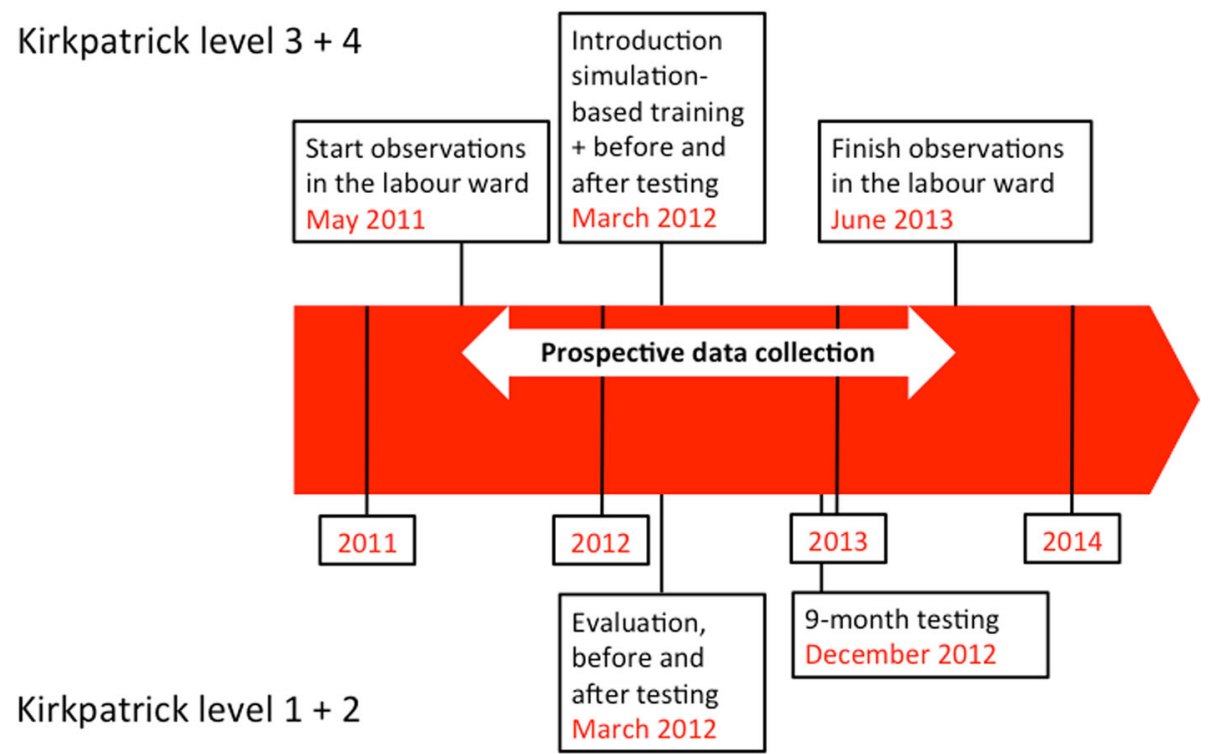

Fig. 2 Timeline

ambulance drivers (without formal education) attended a half-day training course "Helping Mothers Survive Bleeding After Birth". The training was conducted in small groups of maximum six participants per facilitator, and consisted of a mix of theory and hands-on practice using a low-cost low-tech simulator (MamaNatalie, Laerdal Global Health). The learning goals were to be able to independently manage an uncomplicated delivery, including active management of third stage of labour by giving $10 \mathrm{IU}$ of oxytocin within one minute after birth, and management of postpartum haemorrhage including bimanual uterine compression. Further details of the intervention and the evaluation of the training are described elsewhere. [8]

\section{Data measurement}

Sixteen research assistants were trained by the principal investigator to structurally observe all births beyond a gestational age of 28 weeks in the hospital. To ensure interrater reliability, the research assistants had a refresher training every three months. Subsequently, their observation skills were assessed in simulated scenarios and on labour ward. Any apparent deviations in observations were discussed and corrected immediately. The observations took place in a structured manner using a validated data collection form with accompanying standard operating procedures. The following background information was recorded for each birth: antenatal care attendance by checking antenatal cards, gestational age at delivery by measuring fundal symphysis height prior to delivery by the birth attendant (as no 12-week dating scan available), mode of delivery (direct observation), birth weight (direct observation), and training attendance including HMS BAB training (by asking the birth attendant). Furthermore, the primary outcome measure was recorded: incidence of postpartum haemorrhage. Blood loss was measured as was usual practice in Haydom Lutheran Hospital and comprised visual estimation, measurement using scales, or a mix of both. The method of measuring blood loss was also recorded. Postpartum haemorrhage was defined as blood loss of $500 \mathrm{ml}$ or more. Severe postpartum haemorrhage was defined as blood loss of $1000 \mathrm{ml}$ or more. Secondary outcome measures were direct observations and included: use of uterotonic drugs after birth (categorized as: oxytocin $10 \mathrm{IU}$, oxytocin $5 \mathrm{IU}$, none, and other uterotonics such as misoprostol or other dosages of oxytocin), timing of administration of uterotonic drugs, removal of placenta by controlled cord traction, uterine massage, and examination of the placenta. In cases complicated by postpartum haemorrhage, its management was observed: use of uterotonic drugs in addition to those given routinely after birth (categorized as: oxytocin $10 \mathrm{IU}$, ergometrine $0.2 \mathrm{mg}$, none, and other uterotonics such as misoprostol or other dosages of oxytocin), uterine massage, examination of perineum, vagina, and/or episiotomy, bimanual uterine compression, hysterectomy, and units of blood received within $24 \mathrm{~h}$. Lastly, maternal and neonatal outcome at $24 \mathrm{~h}$ were recorded. A research supervisor reviewed the completed data collection forms regularly. In case of missing information or discrepancies, the data collection form was returned to the 
research assistant to be completed in accordance with the original hospital notes under supervision of the research supervisor.

\section{Sample size consideration}

In peer-reviewed articles, incidence rates of postpartum haemorrhage range between 2 and 26\%, depending on the definition of postpartum haemorrhage and the method of measuring blood loss. [2, 3, 24, 25] Based on these data, we hypothesized an incidence of postpartum haemorrhage (defined as blood loss of $500 \mathrm{ml}$ or more) of $10 \%$. To show a $25 \%$ decrease in the incidence of postpartum haemorrhage with $80 \%$ power and a confidence interval of $95 \%$, a sample of 2010 births before, and the same number of births after intervention was needed. If the incidence of postpartum haemorrhage would lie in the lower range cited in the literature (2\%) a sample of 11,153 births would be needed before and after the intervention. If the incidence would be around the upper estimates (26\%), the sample size needed would be 656 births before and after intervention.

\section{Statistical analysis}

Data were entered twice by two different data clerks and crosschecked in EpiData (The EpiData Association, Odense, Denmark). We used IBM SPSS Statistics (version 20) for data-analysis (IBM, Armonk, NY, USA). In order to assess the effect of the intervention, the study period was divided in two: 25th May 2011 to 6th March 2012 (before training) and 13th March 2012 to 25th June 2013 (after training). The training course took place from the 7th to the 12th of March 2012 and this period was excluded from the analysis. Observations before and after training were compared. Descriptive statistics were calculated for the background characteristics of women who delivered during the study period, the clinical performance of healthcare workers attending births (basic delivery skills and management of postpartum haemorrhage), and patient outcome. Results are reported in numbers (n) and proportions (\%) for categorical variables, and mean and standard deviation (SD) for continuous variables. The chi-square test was used for comparison of categorical variables. If numbers were smaller than five, the fisher exact test was used. The independent samples t-test (2-sided) was used to compare continuous variables.

\section{Results}

There were 9446 births observed during the study period from May 2011 to June 2013, 3622 births before and 5824 births after intervention. Ten clinicians were working at the hospital and eight of them attended training $(80 \%)$. Of the 25 nurse-midwives working in labour ward, 15 attended training (60\%), and 14 out of 19 medical attendants attended training (74\%). Six out of ten ambulance drivers were trained (60\%). On average $54.1 \%$ of all births were attended by a HMS BAB trained health care worker. To look at staff turnover, the period after training was divided in three-month periods. In the first three months after training $31.9 \%$ of the births were attended by a HMS BAB trained health care worker. In the second three-month period this proportion was $68.8 \%$, then $57.7 \%, 62.9 \%$, and $48.1 \%$ in the consecutive three-month time periods.

Table 1 summarizes the baseline characteristics. More than $97 \%$ of the women attended antenatal care. This remained constant throughout the entire study period. Women giving birth after training had a slightly higher mean gestational age ( 36.4 weeks) compared to women giving birth before training (36.2 weeks) $(p<0.001)$. Most babies were delivered vaginally (before training $82.4 \%$, after training $81.0 \%$ ). After training more caesarean sections were done (16.1\%) compared to before training $(13.5 \%)(p<0.001)$. Babies born before training had a higher mean birth weight (3107 g) compared to babies born after training (3074 g) $(p=0.001)$.

Table 2 shows patient outcome before and after training. Among the births observed $(n=9446)$ there was a statistically significant difference in blood loss between before (mean $216 \mathrm{ml}$ blood loss, SD $130 \mathrm{ml}$ ) and after intervention (mean $207 \mathrm{ml}$ blood loss, SD $130 \mathrm{ml}$ ) $(\mathrm{p}=0.001)$. However, Cohen's effect size value $(\mathrm{d}=0.07)$ suggested small practical relevance. After training there was a significant reduction in the incidence of postpartum haemorrhage $(500-1000 \mathrm{ml})$ from $2.1 \%$ to $1.3 \%$ $(p=0.003)$. No difference was seen in the group with

Table 1 Baseline characteristics

\begin{tabular}{llll}
\hline & $\begin{array}{l}\text { Before training } \\
(n=3622)\end{array}$ & $\begin{array}{l}\text { After training } \\
(n=5824)\end{array}$ & $P$ value \\
\hline $\begin{array}{l}\text { Antenatal care attendance, } \\
\mathrm{n}(\%)\end{array}$ & $3530(97.5)$ & $5684(97.6)$ & 0.46 \\
$\begin{array}{l}\text { Gestational age, mean } \\
\text { (SD), weeks }\end{array}$ & $36.2(1.1)$ & $36.4(1.3)$ & $<0.001$ \\
$\begin{array}{l}\text { Mode of delivery, n (\%) } \\
\text { Vaginal delivery }\end{array}$ & $2984(82.4)$ & $4717(81.0)$ & 0.07 \\
\multicolumn{1}{c}{ Breech delivery } & $66(1.8)$ & $51(0.9)$ & $<0.001$ \\
$\begin{array}{l}\text { Assisted vaginal delivery } \\
\text { Caesarean section }\end{array}$ & $26(0.7)$ & $25(0.4)$ & 0.06 \\
$\begin{array}{l}\text { Missing } \\
\text { Birth weight, mean } \\
\text { (SD), gram }\end{array}$ & $588(13.5)$ & $940(16.1)$ & $<0.001$ \\
$\begin{array}{l}\text { Births attended by HMS } \\
\text { BAB trained person, } \mathrm{n}(\%)\end{array}$ & $0(0)$ & $91(1.6)$ & 0.001 \\
\hline
\end{tabular}

${ }^{\mathrm{a}}$ In most women there was no reliable estimated date of delivery as calculation by last menstrual period is uncertain and no dating scan facilities are available. Therefore, gestational age was calculated by measuring the fundal symphysis height prior to delivery

**Unable to compute $P$ value as before training no one was trained 
Table 2 Incidence of postpartum haemorrhage and patient outcome before and after intervention

\begin{tabular}{|c|c|c|c|}
\hline & $\begin{array}{l}\text { Before training, } \\
\mathrm{n}(\%)(\mathrm{n}=3622)\end{array}$ & $\begin{array}{l}\text { After training, } n \\
(\%)(n=5824)\end{array}$ & $P$ value \\
\hline \multicolumn{4}{|l|}{ Blood loss } \\
\hline$<500 \mathrm{ml}$ & $3529(97.4)$ & $5721(98.2)$ & 0.008 \\
\hline $500-1000 \mathrm{ml}$ & $77(2.1)$ & $78(1.3)$ & 0.003 \\
\hline$\geq 1000 \mathrm{ml}$ & $16(0.4)$ & $25(0.4)$ & 0.93 \\
\hline \multicolumn{4}{|c|}{ Method of estimating blood loss } \\
\hline Visual & $3236(89.3)$ & $5286(90.8)$ & 0.02 \\
\hline Measured & $165(4.6)$ & $122(2.1)$ & $<.001$ \\
\hline Both & $221(6.1)$ & $416(7.1)$ & 0.05 \\
\hline \multicolumn{4}{|l|}{ Maternal outcome after $24 \mathrm{~h}$} \\
\hline $\begin{array}{l}\text { Admitted to MW, } \\
\text { discharged }<24 \mathrm{~h}\end{array}$ & $1274(35.2)$ & $1594(27.4)$ & $<.001$ \\
\hline $\begin{array}{l}\text { Admitted to MW, } \\
\text { discharged }>24 \mathrm{~h}\end{array}$ & $2331(64.4)$ & $4201(72.1)$ & $<.001$ \\
\hline $\begin{array}{l}\text { Admitted to ICU } \\
<24 \mathrm{~h}\end{array}$ & $16(0.4)$ & $27(0.5)$ & 0.88 \\
\hline Death $<24 \mathrm{~h}$ & $1(0.03)$ & $2(0.03)$ & 0.86 \\
\hline \multicolumn{4}{|l|}{ Perinatal outcome after $24 \mathrm{~h}$} \\
\hline Normal & $3423(94.5)$ & $5494(94.3)$ & $<.001$ \\
\hline Any kind of difficulties & $11(0.3)$ & $58(1.0)$ & $<.001$ \\
\hline Died after birth & $29(0.8)$ & $50(0.9)$ & 0.84 \\
\hline Stillbirth (fresh) & $58(1.6)$ & $68(1.2)$ & 0.07 \\
\hline Stillbirth (macerated) & $43(1.2)$ & $72(1.2)$ & 0.84 \\
\hline Missing & $58(1.6)$ & $82(1.4)$ & \\
\hline
\end{tabular}

MW Maternity Ward, ICU Intensive Care Unit

blood loss more than $1000 \mathrm{ml}$ (before training 0.4\%, after training $0.4 \%$ ). In most cases blood loss was estimated visually (before training 89.3\%, after training $90.8 \%)$. The number of maternal deaths within $24 \mathrm{~h}$ after birth did not change after training $(n=1$ before training versus $n=2$ after training). None of the maternal deaths were attributed to postpartum haemorrhage. Neonatal mortality did not change after training.

Table 3 shows the clinical performance of basic delivery skills before and after training. The proportion of women receiving $10 \mathrm{IU}$ of oxytocin after training (91.7\%) was significantly higher compared to before training (87.8\%). There was no difference in the proportion of women that did not receive uterotonic drugs after delivery (before training 3.0\%, after training 2.9\%). After training, a significantly greater proportion of women received uterotonic drugs within one minute after birth (before training $40.4 \%$, after training $44.3 \%$ ). Removal of placenta by controlled cord traction and subsequent uterine massage were more frequently performed after training $(98.8 \%$ and 99.0\% respectively) compared to before training (96.5\% and $93.0 \%$ respectively). There was no difference in the proportion of women that had their placenta examined
Table 3 Basic delivery skills

\begin{tabular}{|c|c|c|c|}
\hline & $\begin{array}{l}\text { Before training, } \\
\mathrm{n}(\%)(\mathrm{n}=3622)\end{array}$ & $\begin{array}{l}\text { After training, } \\
\mathrm{n}(\%)(\mathrm{n}=5824)\end{array}$ & $P$ value \\
\hline \multicolumn{4}{|l|}{ Uterotonic drugs } \\
\hline Oxytocin, $10 \mathrm{IU}$ & $3180(87.8)$ & $5338(91.7)$ & $<.001$ \\
\hline Oxytocin, $5 \mathrm{IU}$ & $69(1.9)$ & $138(2.4)$ & 0.14 \\
\hline None & $108(3.0)$ & $170(2.9)$ & 0.83 \\
\hline Other & $247(6.8)$ & $178(3.1)$ & $<.001$ \\
\hline Missing & $18(0.5)$ & $0(0)$ & \\
\hline $\begin{array}{l}\text { Uterotonic drugs } \\
\text { administered within } \\
\text { one minute after birth }\end{array}$ & $1465(40.4)$ & $2578(44.3)$ & 0.001 \\
\hline Missing & 139 (3.8) & $176(3.0)$ & \\
\hline $\begin{array}{l}\text { Removal of placenta by } \\
\text { controlled cord traction }\end{array}$ & $3494(96.5)$ & $5757(98.8)$ & $<.001$ \\
\hline Missing & $2(0.1)$ & $0(0)$ & \\
\hline Uterine massage & $3367(93.0)$ & $5767(99.0)$ & $<.001$ \\
\hline Missing & $4(0.1)$ & $0(0)$ & \\
\hline Examination of placenta & $1338(36.9)$ & $2157(37.0)$ & 0.96 \\
\hline Missing & $4(0.1)$ & $0(0)$ & \\
\hline
\end{tabular}

for completeness after delivery (before training 36.9\%, after training $37.0 \%)$.

Table 4 shows management of postpartum haemorrhage before and after training. In the entire study period, 196 women (2.1\%) experienced postpartum haemorrhage of $500 \mathrm{ml}$ blood loss or more. The proportion of women with postpartum haemorrhage receiving $10 \mathrm{IU}$ of oxytocin as part of management of postpartum haemorrhage significantly increased from $43.0 \%$ before training to $61.2 \%$ after training. The proportion of women with postpartum haemorrhage that did not receive any uterotonic drugs increased from $1.1 \%$ before training to $3.9 \%$ after training, but this was not statistically significant. After training, more women received uterine massage (before $80.6 \%$, after $90.3 \%$ ), examination of perineum, vagina, and/or episiotomy (before $51.6 \%$, after 64.1\%), and bimanual uterine compression (before training $11.8 \%$, after training $19.4 \%$ ) as part of the management of postpartum haemorrhage. However, these changes were not statistically significant. The proportion of women having a hysterectomy after postpartum haemorrhage remained constant at around 3\%. The number of blood units given within $24 \mathrm{~h}$ to women experiencing postpartum haemorrhage increased slightly from an average of 0.4 units before training to an average of 0.7 units after training.

\section{Discussion}

Main findings

The incidence of postpartum haemorrhage before the intervention was near the lower limits of the range 
Table 4 Management of postpartum haemorrhage

\begin{tabular}{|c|c|c|c|}
\hline & $\begin{array}{l}\text { Before training, } \\
\mathrm{n}(\%) n=93\end{array}$ & $\begin{array}{l}\text { After training, } \\
\mathrm{n}(\%) n=103\end{array}$ & $P$ value \\
\hline \multicolumn{4}{|l|}{ Uterotonic drugs } \\
\hline Oxytocin, $10 \mathrm{IU}$ & $40(43.0)$ & $63(61.2)$ & 0.04 \\
\hline Ergometrine, $0.2 \mathrm{mg}$ & $12(12.9)$ & $18(17.5)$ & 0.49 \\
\hline None & $1(1.1)$ & $4(3.9)$ & 0.38 \\
\hline Other & $34(36.6)$ & $18(17.5)$ & 0.001 \\
\hline Missing & $6(6.5)$ & $0(0)$ & \\
\hline Uterine massage & 75 (80.6) & $93(90.3)$ & 0.19 \\
\hline Missing & $6(6.5)$ & $2(1.9)$ & \\
\hline $\begin{array}{l}\text { Examination of perineum, } \\
\text { vagina, episiotomy }\end{array}$ & $48(51.6)$ & $66(64.1)$ & 0.16 \\
\hline Missing & $6(6.5)$ & $2(1.9)$ & \\
\hline $\begin{array}{l}\text { Bimanual uterine } \\
\text { compression }\end{array}$ & $11(11.8)$ & $20(19.4)$ & 0.22 \\
\hline Missing & $7(7.5)$ & $0(0)$ & \\
\hline Hysterectomy & $3(3.2)$ & $3(2.9)$ & 0.99 \\
\hline Missing & $7(7.5)$ & $0(0)$ & \\
\hline \multicolumn{4}{|l|}{$\begin{array}{l}\text { Units of blood given } \\
<24 \mathrm{~h}\end{array}$} \\
\hline No blood given & $56(60.2)$ & $59(57.3)$ & 0.26 \\
\hline 1 unit & $23(24.7)$ & $28(27.2)$ & 0.95 \\
\hline$\geq 2$ units & $6(6.5)$ & $15(14.6)$ & 0.10 \\
\hline Missing & $8(8.6)$ & $1(0.9)$ & \\
\hline
\end{tabular}

between $2 \%$ and $26 \%$ found in the literature. [2, 3, 24, 25] Nevertheless, our study showed a $38 \%$ reduction (from 2.1\% before to $1.3 \%$ after training) in the incidence of postpartum haemorrhage $(500-1000 \mathrm{ml})$ following the introduction of the HMS BAB training programme. However, the effect size was low and therefore of small clinical significance, mainly because of the already low incidence before the intervention. The reduction in postpartum haemorrhage was associated with an improvement in clinical performance of basic delivery skills and management of postpartum haemorrhage. The latter was not statistically significant except for an increase in the use of oxytocin for treatment of postpartum haemorrhage. These results are highly relevant considering the high prevalence of anaemia in pregnancy in this population and the fact that most of these settings do not have blood banks. [26]

\section{Strengths and limitations}

The improvements seen after the introduction of the training course may be caused by other changes in the healthcare system. A parallel study on the effect of simulation training in neonatal resuscitation took place around the same time as this study. In addition, the labour ward was expanded during the time of the study.
However, we do not think these changes had any influence on the outcomes studied in this project, as it has not changed practice regarding the prevention and management of postpartum haemorrhage. No new guidelines, protocols, or obstetric initiatives were introduced in the hospital during the study period. Only one person attended an external emergency obstetric care training course. In addition, we have evaluated the HMS BAB programme on all four levels of the Kirkpatrick model. $[8,27]$ Because there is improvement across most levels of the Kirkpatrick model, we consider it very likely that the reduction in incidence of postpartum haemorrhage and improvement in clinical performance was due to the training course.

It was not feasible to power our study to investigate the effect of training on maternal mortality. Based on a cross-sectional study that took place in Haydom Lutheran Hospital from 2009 to 2011, [26] we would expect approximately 16 maternal deaths and maternal near misses related to postpartum haemorrhage (prevalence $0.64 \%$ ) per year. A sample of approximately 70,000 births would be needed to show a reduction of $25 \%$ in postpartum haemorrhage related maternal mortality and severe maternal morbidity.

Gestational age was estimated by measuring the fundal symphysis height. This is most likely not very accurate as the mean birth weight in this cohort was around $3100 \mathrm{~g}$ and the mean gestational age was 36 weeks. However, this method is common practice in most low-resource settings [28] and was used consistently throughout the study period. Therefore, both periods before and after intervention have the same measurement flaw. We have accepted this because of unreliable date of last menstrual period and lack of dating scan possibilities.

Lastly, the presence of research assistants may have influenced the performance of the healthcare workers being observed (Hawthorne effect). We expect this effect to be minimal as the research assistants had been present in labour ward for more than two years, collecting data by observing births for other studies, and were considered part of the team working in labour ward. [29-31]

\section{Interpretation}

The overall incidence of postpartum haemorrhage was almost $8 \%$ lower than expected. Sheldon et al. describe a similar finding in the WHO Multicountry Survey on Maternal and Newborn Health. [32] The measured incidence is most likely to be an underestimation of the actual incidence because in the majority of women blood loss was estimated visually. It is known that subjective measurement of blood loss leads to lower estimates of the incidence of postpartum haemorrhage. [3, 33] Furthermore, in our cohort the proportion of women with postpartum haemorrhage receiving bimanual uterine 
compression and hysterectomy was relatively high, indicating severe bleeding. To objectively measure blood loss, we explored the use of point-of-care $\mathrm{Hb}$ measurements before and after birth and the use of blood collection bags. However, this did not fit our research budget and the idea met resistance from nurse midwives who already experienced a high workload. The likely underestimation of blood loss influences the study power. In the group of women with more than $500 \mathrm{ml}$ blood loss after birth, an improvement in management of postpartum haemorrhage was observed. However, because of the lower than expected incidence of postpartum haemorrhage, our sample size was too small to show a statistically significant difference. It is important to emphasize the need for objective blood loss measurement in future research in low-resource settings. It will not only improve the reliability of the outcomes, but may also improve quality of care in general by better detection of major haemorrhage and subsequent management.

A significant increase in caesarean sections was observed after training. Performing caesarean sections was not addressed during training. We do not know the reason for this increase, other than a reflection of the global increase in caesarean sections, but we know caesarean sections are associated with an increased amount of blood loss after birth compared to vaginal births. [34] This increase in blood loss associated with caesarean sections was not seen after training. Instead a reduction of blood loss was seen. The reduction in postpartum haemorrhage may have been more pronounced if the caesarean section rate would have remained stable.

The results of this study are very relevant for a population in which $76 \%$ of women suffer from anaemia in pregnancy. [26] In addition, in many low-resource settings such as Haydom Lutheran Hospital, there is no blood bank and women depend on their relatives for blood for transfusion. A reduction of haemorrhage in the group with 500-1000 ml blood loss, was assumed to be possible due to improvement in the basic steps of management of postpartum haemorrhage such as giving oxytocin, removing the placenta by controlled cord traction, and performing uterine massage. The mannequin that was used in the HMS BAB training programme has features that very realistically simulate these basic steps: a placenta that can be removed by controlled cord traction, a uterus that can contract and relax, and the ability of the mannequin to bleed up to $1500 \mathrm{ml}$. These features may have helped the learning of these skills. However, in women with severe blood loss after birth $(>1000 \mathrm{ml})$ the basic steps may not have been sufficient enough to control bleeding caused by uterine atony, and certainly not for other causes of postpartum haemorrhage. Therefore, we were not able to observe a reduction in severe postpartum haemorrhage.
HMS BAB was also introduced and evaluated in India, Malawi, and Zanzibar in 2012. [13] This study reported on good acceptability and increase in knowledge and skills after introduction of the training programme, however, it did not report on effect on clinical performance and patient outcome. Currently, the HMS BAB programme is being evaluated in Uganda.

Other studies investigating the impact of obstetric emergency training report mostly on neonatal outcome, and only few studies report on maternal outcome. $[16,17]$ The QUARITE study showed a reduction in maternal mortality after a multifaceted intervention to promote maternity death reviews and onsite training in emergency obstetric care. [20] Two further studies show a decrease in postpartum haemorrhage after introduction of an obstetric training programme. $[18,21]$ Sorensen et al. studied the impact of the Advanced Life Support in Obstetrics (ALSO) course in Tanzania and found no difference in the management of prolonged labour and neonatal care. [35] There was, however, a significant improvement in active management of third stage of labour and management of postpartum haemorrhage after training. [18] The above studies reinforce the results of our study that simulationbased training can be used to improve clinical performance and patient outcome.

\section{Conclusions}

A half-day obstetric simulation-based training HMS BAB was associated with a reduction in the incidence of postpartum haemorrhage $(500-1000 \mathrm{ml})$. Clinical performance of basic delivery skills and treatment of postpartum haemorrhage with oxytocin increased significantly after training. Other skills in management of postpartum haemorrhage (uterine massage, examination of birth canal, and bimanual uterine compression) improved after training, but this was not statistically significant. The study power has suffered from the much lower than anticipated incidence of postpartum haemorrhage. Future research should focus on objective measurement of blood loss and consider using a randomised study design.

\section{Abbreviations}

HMS BAB: Helping Mothers Survive Bleeding After Birth; n: number; PPH: Postpartum Haemorrhage; SD: Standard Deviation

\section{Acknowledgements}

The authors wish to thank the management, research assistants, and staff of Haydom Lutheran Hospital.

\section{Funding}

This study was funded by the Laerdal Foundation for Acute Medicine, Stavanger, Norway. The funders had no role in the design and conduct of the study; collection, management, analysis, and interpretation of the data; and preparation, review, or approval of the manuscript.

\section{Availability of data and materials}

The datasets used and/or analysed during the current study available from the corresponding author on reasonable request. 


\section{Authors' contributions}

Dr. Nelissen had full access to all data in the study and takes responsibility for the integrity of the data and the accuracy of the data analysis. Study concept and design: N, E, M, E-O, VR, S. Statistical analysis: N, T. Acquisition, analysis, or interpretation of data: N, E, M, E-O, T, B, vR, S. Drafting of the manuscript: N. Critical revision of the manuscript: N, E, M, $\mathrm{E}-\mathrm{O}, \mathrm{T}, \mathrm{B}, \mathrm{vR}, \mathrm{S}$. All authors read and approved the final manuscript.

\section{Ethics approval and consent to participate}

Ethical approval was obtained from the Tanzanian National Institute for Medical Research (reference NIMR/HQ/R.8a/Nol.IX/1247), the Tanzania Commission for Science and Technology (reference 2013-41-ER-2011-201), and from the VU University Medical Centre, the Netherlands (reference 2011/ 389). Permission to conduct the study was obtained from the hospital management. Individual consent from observed individuals was not obtained because there were no interventions at individual level. Data was collected without possible identification of the patient and without interfering with treatment or patient outcome.

\section{Consent for publication}

Not applicable.

\section{Competing interests}

Dr. Nelissen received an unconditional stipend from the Laerdal Foundation for Acute Medicine, Stavanger, Norway. Dr. Ersdal holds a post-doctoral position at the Stavanger University Hospital, which is financed by an unrestricted grant from the Laerdal Foundation for Acute Medicine. All other authors do not have any competing interests.

\section{Publisher's Note}

Springer Nature remains neutral with regard to jurisdictional claims in published maps and institutional affiliations.

\section{Author details}

'Research Department, Haydom Lutheran Hospital, POB 9000, Haydom, Manyara, Tanzania. ${ }^{2}$ Department of Obstetrics and Gynaecology, Southmead Hospital, Southmead Road, Bristol BS10 5NB, UK. ${ }^{3}$ Stavanger Acute Medicine Foundation for Education and Research (SAFER), Department of Anaesthesiology and Intensive Care, Stavanger University Hospital, POB 8100, 4068 Stavanger, Norway. ${ }^{4}$ Centre for International Health, University of Bergen, Årstadveien 21, N-5009 Bergen, Norway. ${ }^{5}$ Department of Obstetrics and Gynaecology, Sørlandet Hospital, Engvald Hansens vei 6, 4400 Flekkefjord, Norway. ${ }^{6}$ Department of Epidemiology and Biostatistics, VU University Medical Center, POB 7057, 1007 MB, Amsterdam, The Netherlands. ${ }^{7}$ Faculty of Earth and Life Sciences, Department of Methodology and Applied Biostatistics, VU University Amsterdam, de Boelelaan 1085, $1081 \mathrm{HV}$, Amsterdam, The Netherlands. ${ }^{8}$ Athena Institute, Faculty of Earth and Life Sciences, VU University Amsterdam, de Boelelaan 1085, 1081 HV, Amsterdam, The Netherlands. ${ }^{9}$ Department of Obstetrics, Leiden University Medical Centre, Albinusdreef 2, 2333, ZA, Leiden, The Netherlands. ${ }^{10}$ Department of Obstetrics and Gynaecology, Leeuwarden Medical Centre, Henri Dunantweg 2, 8934 AD, Leeuwarden, The Netherlands. "'Department of Health Sciences, Global Health, University Medical Centre Groningen/University of Groningen, Antonius Deusinglaan 1, 9713 AV, Groningen, The Netherlands.

\section{Received: 21 December 2016 Accepted: 4 September 2017}

\section{Published online: 11 September 2017}

\section{References}

1. Say L, Chou D, Gemmill A, Tuncalp O, Moller A-B, Daniels JG, AM IS, Temmerman M, Alkema L. Global causes of maternal death: a WHO systematic analysis. Lancet Global Health. 2014;2:323-33.

2. Carroli G, Cuesta C, Abalos E, Gulmezoglu AM. Epidemiology of postpartum haemorrhage: a systematic review. Best Pract Res Clin Obstet Gynaecol. 2008; 22(6):999-1012.

3. Calvert C, Thomas SL, Ronsmans C, Wagner KS, Adler AJ, Filippi V. Identifying regional variation in the prevalence of postpartum haemorrhage: a systematic review and meta-analysis. PLoS One. 2012;7(7):e41114.

4. McLean E, Cogswell M, Egli I, Wojdyla D, de Benoist B. Worldwide prevalence of anaemia, WHO vitamin and mineral nutrition information system, 1993-2005. Public Health Nutr. 2009;12(4):444-54.
5. Koblinsky M, Matthews Z, Hussein J, Mavalankar D, Mridha MK, Anwar I, Achadi E, Adjei S, Padmanabhan P, Marchal B, et al. Going to scale with professional skilled care. Lancet. 2006;368(9544):1377-86.

6. National Bureau of Statistics (NBS) Tanzania and ICF Macro. Tanzania demographic and health survey 2010 final report. Tanzania: Dar es Salaam; 2011.

7. Harvey SA, Blandon YC, McCaw-Binns A, Sandino I, Urbina L, Rodriguez C, Gomez I, Ayabaca P, Djibrina S. Are skilled birth attendants really skilled? A measurement method, some disturbing results and a potential way forward. Bull World Health Organ. 2007;85(10):783-90.

8. Nelissen E, Ersdal H, Ostergaard D, Mduma E, Broerse J, Evjen-Olsen B, van Roosmalen J, Stekelenburg J. Helping mothers survive bleeding after birth: an evaluation of simulation-based training in a low-resource setting. Acta Obstet Gynecol Scand. 2014;93(3):287-95.

9. Jhpiego. Helping Mothers Survive Bleeding after Birth [https://hms.jhpiego. org/] Accessed 8 Sept 2017.

10. Jhpiego. Helping Mothers Survive Bleeding After Birth Training Package [http://reprolineplus.org/resources/HMS]. Accessed 8 Sept 2017.

11. Mosley C, Dewhurst C, Molloy S, Shaw BN. What is the impact of structured resuscitation training on healthcare practitioners, their clients and the wider service? A BEME systematic review: BEME guide no. 20. Med Teach. 2012; 34(6):e349-85.

12. van Lonkhuijzen L, Dijkman A, van Roosmalen J, Zeeman G, Scherpbier A. A systematic review of the effectiveness of training in emergency obstetric care in low-resource environments. BJOG. 2010;117(7):777-87.

13. Evans $\mathrm{CL}$, Johnson $\mathrm{P}$, Bazant $\mathrm{E}$, Bhatnagar N, Zgambo J, Khamis AR. Competency-based training "helping mothers survive: bleeding after birth" for providers from central and remote facilities in three countries. Int J Gynaecol Obstet. 2014;126(3):286-90.

14. Kirkpatrick D. Evaluating training programs: the four levels. 3rd ed. BerrettKoehler: Oakland, California; 2008.

15. McGaghie WC, Issenberg SB, Petrusa ER, Scalese RJ. A critical review of simulationbased medical education research: 2003-2009. Med Educ. 2010;44(1):50-63.

16. Smith A, Siassakos D, Crofts J, Draycott T. Simulation: improving patient outcomes. Semin Perinatol. 2013;37(3):151-6.

17. Bergh A-M, Baloyi S, Pattinson RC. What is the impact of multi-professional emergency obstetric and neonatal care training? Best Pract Res Clin Obstet Gynaecol. 2015;29(8):1028-43.

18. Sorensen BL, Rasch V, Massawe S, Nyakina J, Elsass P, Nielsen BB. Advanced life support in obstetrics (ALSO) and post-partum hemorrhage: a prospective intervention study in Tanzania. Acta Obstet Gynecol Scand. 2011;90(6):609-14.

19. Walton A, Kestler E, Dettinger JC, Zelek S, Holme F, Walker D. Impact of a low-technology simulation-based obstetric and newborn care training scheme on non-emergency delivery practices in Guatemala. Int J Gynecol Obstet. 2016;132(3):359-64.

20. Dumont A, Fournier P, Abrahamowicz M, Traoré M, Haddad S. Fraser WD, group Qr: quality of care, risk management, and technology in obstetrics to reduce hospital-based maternal mortality in Senegal and Mali (QUARITE): a cluster-randomised trial. Lancet. 2013;382(9887):146-57.

21. Spitzer RF, Steele SJ, Caloia D, Thorne J, Bocking AD, Christoffersen-Deb A Yarmoshuk A, Maina L, Sitters J, Chemwolo B. One-year evaluation of the impact of an emergency obstetric and neonatal care training program in western Kenya. Int J Gynecol Obstet. 2014;127(2):189-93.

22. Grunebaum A, Chervenak F, Skupski D. Effect of a comprehensive obstetric patient safety program on compensation payments and sentinel events. Am J Obstet Gynecol. 2011;204(2):97-105.

23. The United Republic of Tanzania: Population and housing census- village and street statistics, age and sex distribution, Manyara Region. Edited by Central Census Office NBoS, President's Offices, Planning and Privatisation, vol. VII. Dar es Salaam; 2005.

24. Oyelese $Y$, Ananth CV. Postpartum hemorrhage: epidemiology, risk factors, and causes. Clin Obstet Gynecol. 2010;53(1):147-56.

25. Bais JM, Eskes M, Pel M, Bonsel GJ, Bleker OP. Postpartum haemorrhage in nulliparous women: incidence and risk factors in low and high risk women. A Dutch population-based cohort study on standard $(>$ or $=500 \mathrm{ml}$ ) and severe $(>$ or $=1000 \mathrm{ml}$ ) postpartum haemorrhage. Eur J Obstet Gynecol Reprod Biol. 2004;115(2):166-72.

26. Nelissen E, Mduma E, Ersdal HL, Evjen-Olsen B, van Roosmalen JJ, Stekelenburg J. Maternal near miss and mortality in a rural referral hospital in northern Tanzania: a cross-sectional study. BMC Pregnancy Childbirth. 2013;13:141. 
27. Nelissen E, Ersdal H, Mduma E, Evjen-Olsen B, Broerse J, van Roosmalen J, Stekelenburg J. Helping mothers survive bleeding after birth: retention of knowledge, skills, and confidence nine months after obstetric simulationbased training. BMC pregnancy and childbirth. 2015:15(1):1.

28. White LJ, Lee SJ, Stepniewska K, Simpson JA, Dwell SLM, Arunjerdja R, Singhasivanon P, White NJ, Nosten F, McGready R. Estimation of gestational age from fundal height: a solution for resource-poor settings. J R Soc Interface. 2012;9(68):503-10.

29. Ersdal HL, Mduma E, Svensen E, Perlman JM. Early initiation of basic resuscitation interventions including face mask ventilation may reduce birth asphyxia related mortality in low-income countries: a prospective descriptive observational study. Resuscitation. 2012;83(7):869-73.

30. McCambridge J, Witton J, Elbourne DR. Systematic review of the Hawthorne effect: new concepts are needed to study research participation effects. J Clin Epidemiol. 2014:67(3):267-77.

31. Ersdal HL, Mduma E, Svensen E, Perlman J. Birth asphyxia: a major cause of early neonatal mortality in a Tanzanian rural hospital. Pediatrics. 2012;129(5): e1238-43.

32. Sheldon WR, Blum J, Vogel JP, Souza JP, Gulmezoglu AM, Winikoff B. Postpartum haemorrhage management, risks, and maternal outcomes: findings from the World Health Organization multicountry survey on maternal and newborn health. BJOG. 2014;121(Suppl 1):5-13.

33. Patel A, Goudar SS, Geller SE, Kodkany BS, Edlavitch SA, Wagh K, Patted SS, Naik VA, Moss N, Derman RJ. Drape estimation vs. visual assessment for estimating postpartum hemorrhage. Int J Gynaecol Obstet. 2006;93(3):220-4.

34. Lumbiganon P, Laopaiboon M, Gulmezoglu AM, Souza JP, Taneepanichskul S, Ruyan P, Attygalle DE, Shrestha N, Mori R, Nguyen DH, et al. Method of delivery and pregnancy outcomes in Asia: the WHO global survey on maternal and perinatal health 2007-08. Lancet. 2010;375(9713):490-9.

35. Sorensen BL, Rasch V, Massawe S, Nyakina J, Elsass P, Nielsen BB: Impact of ALSO training on the management of prolonged labor and neonatal care at Kagera regional hospital, Tanzania. Int J Gynecol Obstet 2010, 111(1):8-12.

\section{Submit your next manuscript to BioMed Central and we will help you at every step:}

- We accept pre-submission inquiries

- Our selector tool helps you to find the most relevant journal

- We provide round the clock customer support

- Convenient online submission

- Thorough peer review

- Inclusion in PubMed and all major indexing services

- Maximum visibility for your research

Submit your manuscript at www.biomedcentral.com/submit

) Biomed Central 